programs is that they do not allow the theorist to take too much for granted; this constraint can liberate the imagination. The truth is that Bruner has no taste for this sort of theorizing, perhaps because he lacks the necessary background. Indeed, at one point, he refers to himself as a "nonscientist".

The danger of a dislocation between Bruner's scientific and humanistic tendencies reaches a maximum in his essay on consciousness. He distinguishes its evolutionary origin as a "tool" for solving problems from its "ornamental" role as a vehicle for "making visible the unseen, making possible the unimagined"'. He draws a parallel distinction between two modes of discourse - the formal scientific mode, and the narrative mode of the poet and myth-maker. The essay itself jumps from one mode to the other, its very form buckling under the pressure.

After the triumphs of the "New Look" and the study of thought, which were both to launch a thousand experiments into the literature, Bruner shifted his attention to schools, and to the reform of the curriculum. His best ideas were thwarted by politicians, but he nonetheless served to shape certain aspects of the educational system in the United States. Subsequently, he returned to the laboratory to investigate children's cognitive development. As he candidly admits, his work here was too close to Piaget's, and it was less well received. At the beginning of the 1970s after the Harvard Center had been disbanded, Bruner, always ready to move, came to England to the Watts professorship of psychology at Oxford. One of the most absorbing essays in the book describes his life in universities, and compares Harvard and Oxford to the latter's disadvantage. In retrospect, one can see that although the Oxford intellectual milieu suited him, the department of psychology did not. It lay entirely on the scientific side of the border, whereas he retained his scepticism. Ultimately, bored by "Bruner-bashing"' seminars, he returned to the United States.

Although Bruner has written a number of widely praised books, this one is his best. Its success rests on two factors. One is Bruner's talent for being at the centre of the cognitive revolution. The other is his skill in re-creating on paper his own personality and cast of mind - a vivid, and very unEnglish mixture of passion, restlessness, gregariousness and intellectuality. He is indeed an intellectual first, a psychologist second and a scientist third. His book is bound to be widely read by psychologists; it should be read by anyone who wants to understand what has happened to American psychology in the past half century.

P.N. Johnson-Laird is Assistant Director of the Medical Research Council's Applied Psychology Unit, Cambridge. His most recent book, Mental Models, was published by Cambridge University Press late last year.

\section{Through to another dimension}

\section{Thomas Banchoff}

The Planiverse: Computer Contact with a Two-Dimensional World.

By A. K. Dewdney.

Poseidon, New York: 1984. Pp.267.

Hbk \$16.95, pbk \$9.95. To be

published in the UK on 11 May by

Picador, hbk £7.95, pbk£2.95.

ONE hundred years ago Nature published a review of Flatland: A Romance of Many Dimensions, Edwin Abbott Abbott's classic tale of A Square, a two-dimensional creature who encounters a visitor from the third dimension. Now there appears a new book, The Planiverse by Alexander Keewatin Dewdney, hailed by the publishers as a worthy successor to Flatland. For those of us who received our first challenge to think about lower and higher dimensions from Abbott's little volume, this claim must be viewed with scepticism. Yet the claim is correct.

Dewdney's volume is a fable for our own time that will delight anyone who likes a good story and who enjoys a mindstretching experience. Subtitled Computer Contact with a Two-Dimensional World, the book introduces us to "Yndrd" (Yendred), a creature we meet only on the video screen of a professor of computer science, Dewdney himself, and his team of students. The progressive encounters which intermesh the world of the observers and the world of the observed lead to an amazingly rich description of Arde, a twodimensional planet, complete with a welldeveloped technological society, worked out in fascinating detail. But this is no video game and still less a dry treatise on two-dimensional science. It is simultaneously a fine tale of adventure, as we accompany Yendred on his trek in search of higher meaning for existence, and the story of Dewdney and his students as they become caught up in the experience and are themselves educated through their contact with Arde.

The original reviewer of Flatland found some parts of the book tedious, as A Square went on at length about the physiology and psychology of perception, or described his society's blinkered view of women's education (an effective satirical device by Abbott, a distinguished schoolmaster well known for his liberal leadership in the cause of education for women). Similarly some readers of The Planiverse will find parts of it slow going, even though the author has relegated many technical asides to special boxes or to an appendix. Yet the pace of the book gives assurance that each new chapter will present something quite different, as the author strives to include material of interest to a wide range of readers - biology, astronomy,

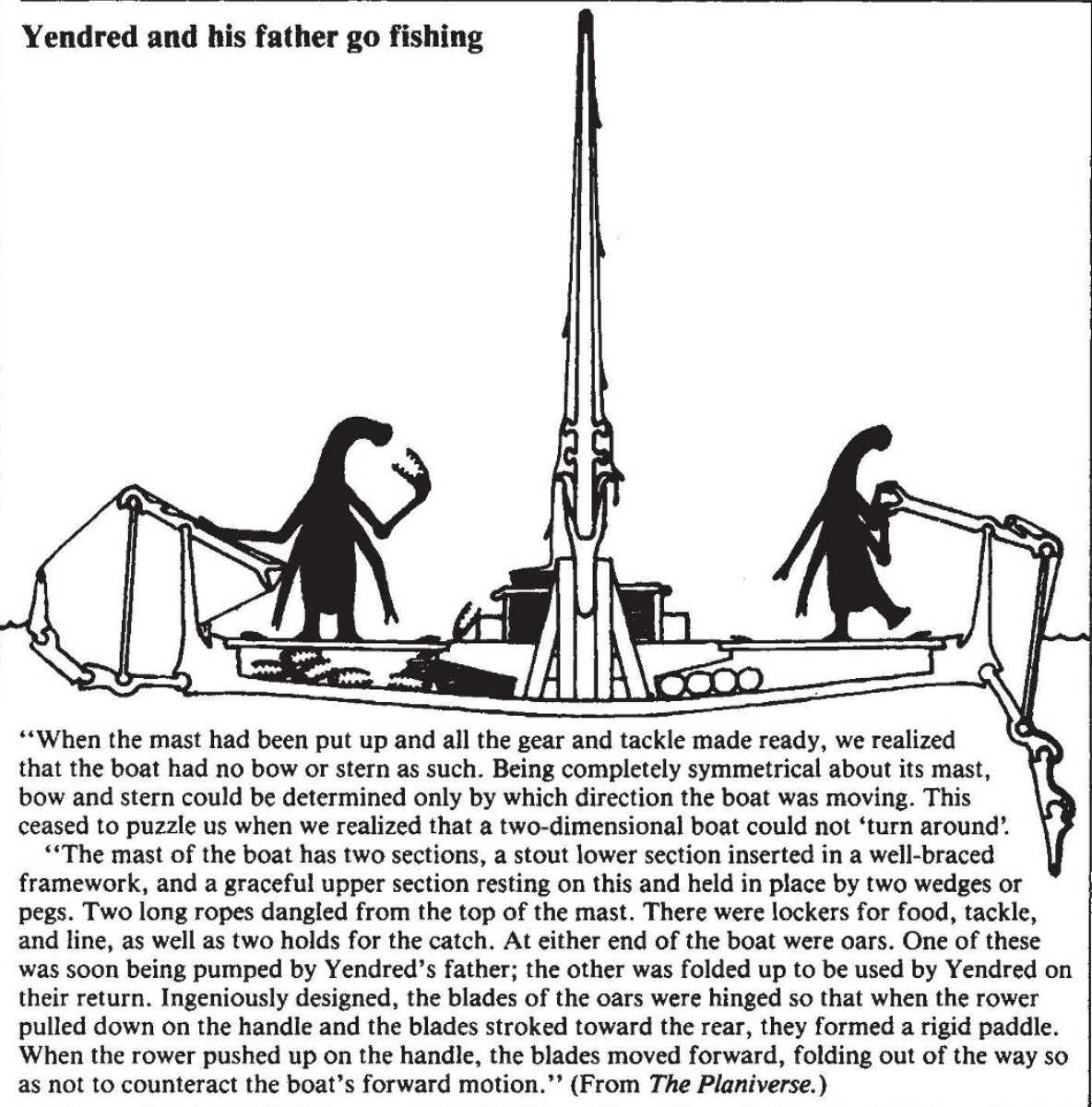

